Piloto et al., 2019

Volume 5 Issue 2, pp. 48-67

Date of Publication: 27th August 2019

DOI-https://dx.doi.org/10.20319/mijst.2019.52.4867

This paper can be cited as: Piloto, P. A. G., Balsa, C., Ribeiro, F., Santos, L., Rigobello, R., E Kimura, É., (2019). Three-Dimensional Numerical Modelling of Fire Exposed Composite Slabs with Steel Deck.

MATTER: International Journal of Science and Technology, 5(2), 48-67.

This work is licensed under the Creative Commons Attribution-Non Commercial 4.0 International License. To view a copy of this license, visit http://creativecommons.org/licenses/by-nc/4.0/ or send a letter to Creative Commons, PO Box 1866, Mountain View, CA 94042, USA.

\title{
THREE-DIMENSIONAL NUMERICAL MODELLING OF FIRE EXPOSED COMPOSITE SLABS WITH STEEL DECK
}

\author{
Paulo A. G. Piloto \\ Professor, Polytechnic Institute of Bragança (IPB), Bragança, Portugal \\ ppiloto@ipb.pt \\ Carlos Balsa \\ Professor, Polytechnic Institute of Bragança (IPB), Bragança, Portugal \\ balsa@ipb.pt \\ Fernando Ribeiro \\ Student, Federal University of Technology - Paraná (UTFPR), Campo Mourão, Brazil \\ fernandoribeiro@alunos.utfpr.edu.br \\ Lucas Santos \\ Student, Federal University of Technology - Paraná(UTFPR), Curitiba, Brazil \\ lucasobmep@outlook.com \\ Ronaldo Rigobello \\ Professor, Federal University of Technology - Paraná(UTFPR), Campo Mourão, Brazil \\ rigobello@utfpr.edu.br \\ Érica Kimura \\ Professor, Federal University of Technology - Paraná (UTFPR), Curitiba, Brazil \\ ekimura@utfpr.edu.br
}

\begin{abstract}
Composite slabs with reinforced concrete and cold-formed profiled steel deck are very popular and reduce the building construction time. The steel deck acts as a permanent formwork to the
\end{abstract}


concrete topping. Usually, the concrete is reinforced with individual rebars placed within the ribs for positive bending, and a steel mesh on the top for negative bending and to prevent concrete cracking. The fire rating of these building elements involves the analysis of different criteria, namely load bearing $(R)$, integrity $(E)$ and insulation $(I)$. The integrity is easily verified, due to the construction method. The other two metrics require the development of experimental fire tests, the application of simplified calculation methods or the development of advanced calculation models. This investigation introduces 3-D numerical validation models for load bearing $(R)$ and insulation (I) criteria. Parametric analyses are developed to investigate the effect of the load into the fire resistance $(R)$ and critical temperature of the steel components (deck, rebar and mesh), as well as the effect of the concrete thickness on the fire resistance from the insulation standpoint (I). The advanced calculation model consists of a non-linear analysis for the thermal and structural behaviour. Both thermal and mechanical models consider perfect contact between materials. For the thermal model, an alternative model is used, with an air gap included between the steel deck and concrete topping to simulate debonding effects. For the mechanical model, the live load level changes from $1.0 \mathrm{kN} / \mathrm{m}^{2}$ to $21.0 \mathrm{kN} / \mathrm{m}^{2}$, and the dead load presents a constant value of $2.8 \mathrm{kN} / \mathrm{m}^{2}$. The fire resistance is determined according to standards, based on the maximum displacement or the rate of displacement. The critical temperature of each steel component decreases with the load level. A new proposal is presented for the critical temperature of each steel component and for the fire resistance according to the insulation criterion.

\section{Keywords}

Composite Slabs with Steel Deck, Fire Resistance, Insulation Criterion, Load Bearing Criterion, Critical Temperature, Numerical Simulation

\section{Introduction}

A composite steel-concrete slab consists of a concrete topping cast on the top of a profiled steel deck. Usually, the concrete is reinforced with an anti-crack mesh positioned on the upper part and individual reinforcing bars placed within the ribs, see Figure 1. The steel deck acts as a permanent formwork and the composite action between the steel and concrete is generally achieved by indentations or embossments in the steel deck. Due to the reinforcement provided by the steel deck, composite slabs are generally slenderer and more efficient than flat concrete slabs, because require less additional reinforcement and less concrete as well. The reduction of the 
construction time, simplicity of installation, and reduction/elimination of struts are other advantages of composite slabs that should be highlighted.

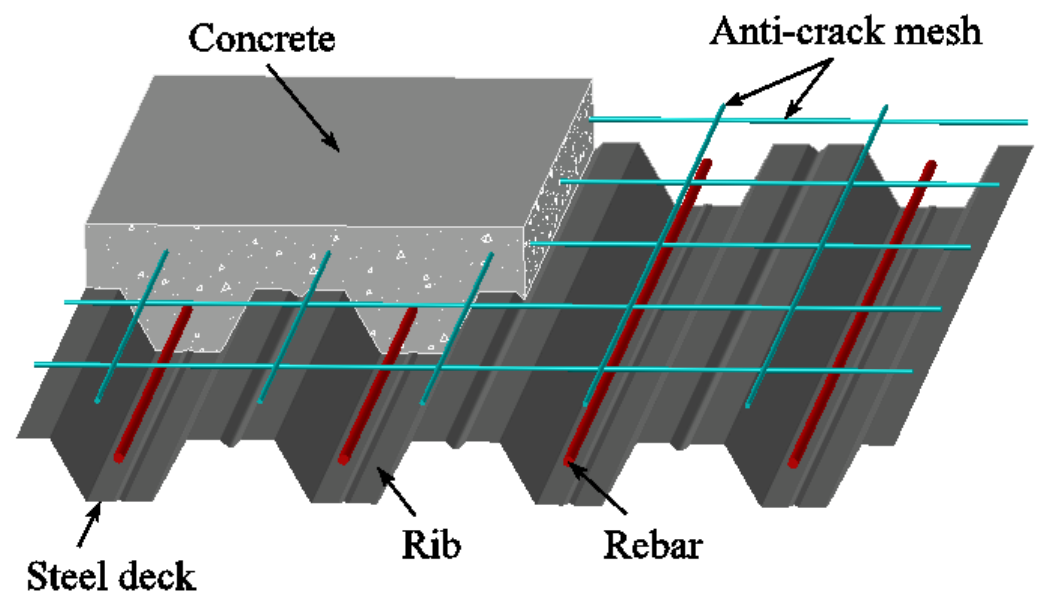

Figure 1: Typical Layout of a Composite Slab with Trapezoidal Steel Deck

Since the decade of 1980, a significant increase in the use of composite slabs with steel deck has taken place in Europe. The most popular types of shapes of the profiled steel deck are trapezoidal and re-entrant. Owing to the ease of casting concrete, slabs with trapezoidal steel deck are more popular than re-entrant ones. The overall depth of composite slabs usually varies between 100 and $170 \mathrm{~mm}$, and the steel deck thickness between 0.7 and $1.2 \mathrm{~mm}$. Generally, the steel deck is protected with a zinc layer on both faces in order to prevent corrosion and increase durability.

The steel deck may be directly exposed to accidental fire conditions. Composite slabs have to meet fire-safety requirements in accordance to standards and regulations. Normally, this structural element is fire rated on the basis of standard fire tests using the standard fire curve ISO 834 (International Organization for Standardization, 1999). The fire resistance should be determined according to three different criteria, namely Load Bearing (R), Integrity (E) and Insulation (I).

The profiled geometry of the steel deck and the presence of the ribs in composite slabs create an orthotropic profile, resulting in complex thermal gradients, hence presenting challenges in numerical modelling (Jiang, Pintar, Weigand, Main, \& Sadek, 2019). In recent years, several studies have been conducted in order to investigate the fire behaviour of this structural element.

In 1983, recognizing the need for a calculation method, the European Convention for Constructional Steelwork (ECCS) (European Convention for Constructional Steelwork Committee T3 - Fire Safety of Steel Structures, 1983) published the first instructions applied to 
the design of composite slabs with profiled steel deck under standard fire conditions. This document introduced simple calculation rules, which were based on the results of fire tests performed on different European laboratories, enabling the fire resistance of composite slabs to be quickly calculated. At this time, the knowledge around the fire behaviour of composite slabs was incomplete and conservative assumptions were adopted, resulting in uneconomical solutions.

In 1990, the first draft of Eurocode 4 - Part 1-2 was presented at a symposium in Luxembourg. The section related to the design of composite slabs of this version was based on the recommendations from the ECCS technical note. Members of the European Community were invited to contribute by sending comments and suggestions. A redrafting started in 1991, but the final version for voting was approved in 1993 (R. Hamerlinck \& Twilt, 1995).

In 1991, Hamerlinck (A. F. Hamerlinck, 1991) conducted a numerical and experimental study regarding the thermal and mechanical behaviour of reinforced composite slabs under fire conditions. Both numerical models were experimentally validated with loaded and unloaded tests. The testing programme took into consideration the most important parameters for fire resistance and a new computer program was developed, enabling simulations at low computational cost (low time processing). It was concluded that the developed two-dimensional model provided satisfactory results, although not including three-dimensional thermal effects.

In 1998, an investigation was carried out by Both (Both, 1998) with the main objective of introducing easy to handle calculation rules as well as providing more insight on the fire behaviour and failure mechanisms mainly of continuous composite slabs. The numerical models were validated against the results of experimental tests performed by the author and other researchers. Finally, a parametric study was performed and simple calculation rules were derived from the results using standard regression techniques. It was concluded that the thermal model was able to describe the two and three-dimensional heat flow in composite slabs during fire exposure and the assessment rules for the fire resistance given in Eurocode 4 at that time could be considerably improved, among other conclusions.

In 2002, Lim and Wade (Lim \& Wade, 2002) performed fire tests on six large-scale concrete slabs, comprising three reinforced concrete flat slabs and three composite steel-concrete slabs. The main objective of the tests was to analyse the fire behaviour of unrestrained simply supported slabs in a controlled furnace. The slabs were subjected to a live load and standard fire conditions during three hours. All the slabs resisted the full duration of the tests without collapsing, 
despite presenting extensive surface cracking on the unexposed surface and large deflections (up to $270 \mathrm{~mm}$ ). In general, the measured fire resistance was higher than the predictions from normative recommendations. The results evidenced the important effect of membrane action on preserving the structural stability of the slabs under fire conditions.

In 2005, the European Commission for Standardization (CEN), published updated design rules for composite steel and concrete structures under fire conditions, EN 1994-1-2 (CENEuropean Committee for Standardization, 2005b). For this version of the standard, the calculation rules for composite slabs were based on the study conducted by Both in 1998. Regarding the insulation criterion (I), the Annex D presents a simplified calculation method, which depends on the geometry of the steel deck, the thickness of concrete above the steel deck and the view factor of the upper flange.

In 2011, Guo and Bailey (Guo \& Bailey, 2011) executed an experimental investigation with the aim of providing more insight on the behaviour of composite slabs during heating and cooling phases of fire. The specimens were loaded with representative values found in practice in order to investigate the structural behaviour. The results showed that the maximum temperature and both heating and cooling rates strongly affected the behaviour of the slabs. For all the tests, the maximum temperatures at the unexposed surface and on the mesh were both higher during the cooling stages, due to the thermal inertial effect. Therefore, it was observed that insulation failure is likely to occur not only during heating but also during the cooling phase.

In 2017, four full-scale fire tests were carried out by Li, Zhang and Jiang (Li, Zhang, \& Jiang, 2017) on composite slabs with profiled steel deck. The main objective of this investigation was to study the influence of the boundary conditions, reinforcement location, slab layout as well as the effect of unprotected secondary beams on tensile membrane action. A comparison between experimental results and Eurocode 4 provisions showed that the simplified calculation method for fire resistance results on conservative assumptions. Concerning the mechanical behaviour, the tensile membrane action provided a considerable contribution to the load bearing capacity. During the tests, significant debonding between the steel deck and concrete topping was observed.

In 2019, Jian Jiang et al. (Jiang et al., 2019), from the National Institute of Standards and Technology (NIST), conducted a numerical investigation around different parameters that may influence on the fire resistance of composite slabs with respect to the thermal insulation criterion (I). An improved algebraic expression for the calculation of the fire resistance that explicitly 
accounts for moisture content of concrete was proposed. The formulation is applicable to an extended range of geometries in comparison to the limitations presented in the current version of Eurocode 4. It was concluded that the concrete thickness and the moisture content were the parameters that most influenced the fire resistance. The proposed expression for fire resistance was validated against additional analyses and experimental data, resulting in maximum deviations of 15 and 18 minutes, respectively.

The scope of this investigation concerns numerical simulations using the standard fire curve ISO 834 with the objective to evaluate the fire resistance according to both insulation (I) and load bearing $(\mathrm{R})$ criteria. Three-dimensional thermal and mechanical analyses are conducted to investigate the effects of standard fire exposure. With respect to the thermal model, an alternative model is utilized, including an air gap with constant thickness between the steel deck and concrete topping in order to simulate debonding effects. Effectively, previous studies mention the separation between the steel deck and concrete during fire exposure, which increases the thermal resistance in this interface.

For both thermal and mechanical models, the numerical simulations are validated against experimental results of a fire test performed by Hamerlinck (A. F. Hamerlinck, 1991). In addition, a comparison between the fire resistance obtained numerically, experimentally and analytically (simplified calculation method of Eurocode 4 - Part 1-2) is presented.

\section{Fire Resistance Criteria}

Structural elements need to meet fire-safety requirements according to building codes. For composite slabs, the requirements are normally specified by fire ratings of 30, 60, 90 minutes or more. The fire rating of this type of building element is usually made using standard fire tests (CEN - European Committee for Standardization, 2012; CEN - European Committee for Standardization, 2014) and should consider the criteria of Insulation (I), Integrity (E) and Load Bearing (R). Generally, experimental fire tests are expensive and time-consuming. As an alternative solution, the fire resistance can be evaluated by means of numerical simulations and using simplified calculation methods. The fire resistance of the composite slabs is defined with respect to standard fire exposure from below. In this investigation, the fire resistance is investigated with respect to both load bearing $(\mathrm{R})$ and thermal insulation (I) criteria. 
The thermal insulation criterion (I) is the ability to withstand fire in one side and prevent excessive transmission of heat. The assessment shall be made on the basis of the average temperature rise on the unexposed surface limited to $140{ }^{\circ} \mathrm{C}$ above the initial average temperature, or; on the basis of the maximum temperature rise at any point on the unexposed surface limited to $180{ }^{\circ} \mathrm{C}$ above the initial average temperature.

The integrity criterion (E) is the capacity to withstand fire in one side and resist penetration of hot gases and flames. The assessment should be made on the basis of measuring cracks or openings in excess of given dimensions, or the ignition of a cotton pad, or sustained flaming on the unexposed side. For cast in situ composite slabs, the integrity criterion is normally satisfied provided that the joints are adequately sealed.

The load bearing resistance for flexural loaded elements $(\mathrm{R})$ is the ability to support the loading during the test without collapsing. The assessment shall be made on the basis of limiting vertical displacement $\mathrm{D}\left(\mathrm{D}=\mathrm{L}^{2} / 400 \mathrm{~d}[\mathrm{~mm}]\right)$, or limiting rate of vertical displacement $(\mathrm{dD} / \mathrm{dt}=$ $\mathrm{L}^{2} / 9000 \mathrm{~d}[\mathrm{~mm} / \mathrm{min}]$ ), being $\mathrm{L}$ the clear span of the testing specimen in millimetres and $\mathrm{d}$ is the distance from the extreme fibre of the cold design compression zone to the extreme fibre of the cold design tensile zone of the structural section, in millimetres.

\section{Description of the Experimental Fire Test}

An experimental fire test conducted by Hamerlinck (A. F. Hamerlinck, 1991) (test number 2) was selected to perform the numerical simulations for the validation of both thermal and mechanical models. The slab was composed by the trapezoidal steel deck PRINS PSV 73 and a concrete topping of $70 \mathrm{~mm}$. The simply supported composite slab was exposed to the ISO 834 standard fire from bellow in a controlled furnace. The profile of the slab is depicted in Figure 2.

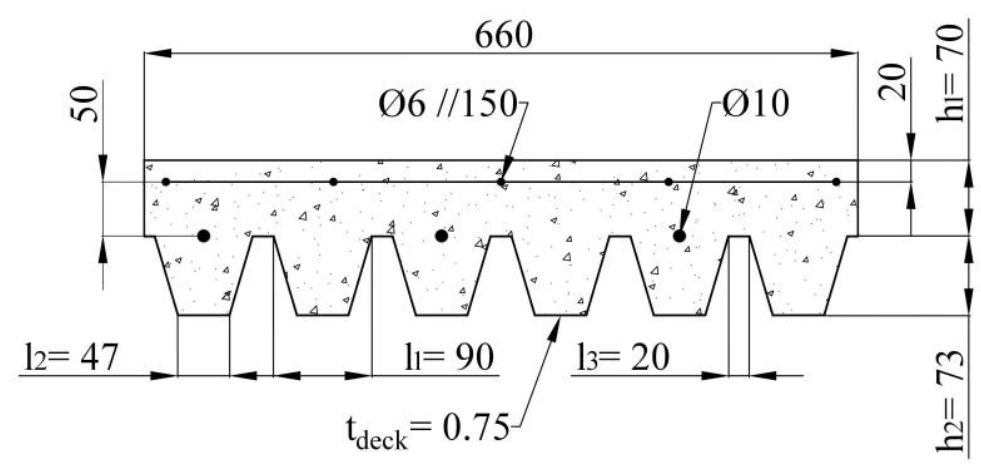

Figure 2: Profile of the Tested Slab: Dimensions in Millimetres (A. F. Hamerlinck, 1991). 
The specimen had a clear span of $660 \mathrm{~mm}$ by $3200 \mathrm{~mm}$. Normal weight concrete was used and the moisture content amounted to $3.5 \%$ by weight. The mechanical load was distributed over four lines, with a spacing of $800 \mathrm{~mm}$, as represented in Figure 3.

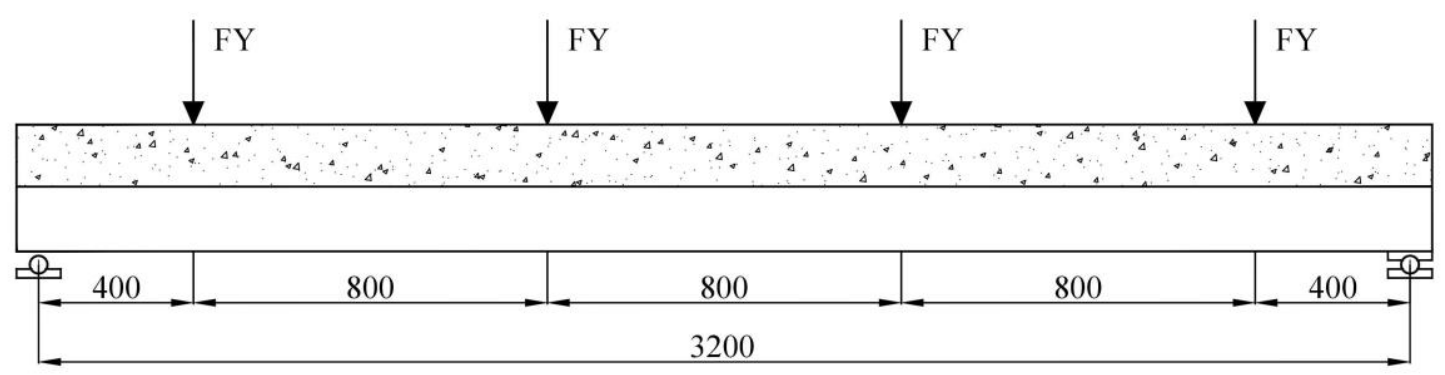

Figure 3: Representation of the Mechanical Model

\section{Validation of the Numerical Models}

The numerical models used to simulate the thermal and mechanical effects caused by the standard fire exposure are presented in this section. A comparison between the results of the numerical simulations and experiments is also presented.

\subsection{Thermal Model}

The composite slab is meshed to solve a non-linear transient thermal analysis, using 3-D models from ANSYS and MATLAB PDE Toolbox. The finite element method (FEM) requires the solution of Eq. 1 in the domain and the definition of the boundary conditions in Eq. 2 at the exposed and unexposed side of the slab.

$$
\begin{array}{r}
\nabla\left(\lambda_{(T)} \cdot \nabla T\right)=\rho_{(T)} \cdot C p_{(T)} \cdot \partial T / \partial t \\
\lambda_{(T)} \cdot \nabla T \cdot \vec{n}=\alpha_{c} \cdot\left(T_{g}-T\right)+\Phi \cdot \varepsilon_{m} \cdot \varepsilon_{f} \cdot \sigma \cdot\left(T_{g}^{4}-T^{4}\right)
\end{array}
$$

In the equations above: $T$ represents the temperature of each material; $\rho_{(T)}$ is the specific mass; $C p_{(T)}$ is the specific heat; $\lambda_{(T)}$ is the thermal conductivity; $\alpha_{c}$ is the convection coefficient; $T_{g}$ represents the gas temperature of the fire compartment, considering the standard fire ISO 834 applied on the bottom part of the slab; $\Phi$ is the view factor; $\varepsilon_{m}$ is the emissivity of each material; $\varepsilon_{f}$ represents the emissivity of the fire and $\sigma$ represents the Stefan-Boltzmann constant.

The view factor $(\Phi)$ quantifies the geometric relation between the surface emitting radiation and the surface receiving radiation. The view factor of the lower flange of composite slabs $\left(\Phi_{\text {low }}\right)$ is given as 1 . Owing to the obstruction to direct fire exposure caused by the ribs of the steel deck, the view factors of the web $\left(\Phi_{w e b}\right)$ and upper flange $\left(\Phi_{\text {upper }}\right)$ are smaller than one. These 
view factors can be calculated as function of the geometric parameters of the slab, as follows, see Eq. 3 and Eq. 4.

$$
\Phi_{\text {web }}=\frac{\sqrt{h_{2}^{2}+\left(\frac{\left.l_{3}+\frac{l_{1}-l_{2}}{2}\right)^{2}}{2}-\sqrt{h_{2}}\right)^{2}+\left(\frac{l_{1}-l_{2}}{2}\right)^{2}}}{l_{3}}
$$

In ANSYS, three different finite elements are used: SHELL131, SOLID70 and LINK33. The SHELL131 element has four nodes with up to 32 degrees of freedom (temperature) per node, depending on the number of layers (one layer). This element presents linear interpolating functions in the plane of the element, using full Gauss integration method (2x2) and linear interpolating functions through the layer thickness (three Gauss points). The shell element is used to model the steel deck of the composite slab. The bottom temperature of shell element nodes is assumed to be equal to the temperature of solid element nodes, when both nodes are coincident (perfect contact). The SOLID70 element presents a hexahedron with eight nodes with a single degree of freedom (temperature) at each node. Linear interpolating functions are used for this element and the full Gauss integration method is also applied $(2 \times 2 \times 2)$. This finite element is used to model the concrete topping and, in the alternative model, the air gap volume. The LINK33 element has two nodes with a single degree of freedom (temperature) per node. This uniaxial element presents linear interpolating functions as well as exact integration. The LINK33 element is used to model the anticrack mesh and the rebars.

In MATLAB, the geometry is meshed through the Partial Differential Equation Toolbox (PDE) with only linear tetrahedral (solid) finite elements. The toolbox does not support meshes with elements of different types. This element has four nodes (one node at each corner) and a single degree of freedom (temperature) at each node. Linear interpolating functions are used for this element.

A three-dimensional model of the slab is generated, which is composed by subdomains that correspond to the different materials: the concrete topping, steel deck, rebars and steel mesh on ANSYS; and concrete topping and steel deck on MATLAB. Previously, a parametric study performed by the authors evidenced that the steel components within the concrete topping does 
not affect the fire resistance with respect to the thermal insulation criterion. Therefore, by means of simplification, these components are not included in the 3-D MATLAB numerical model. Concerning the alternative model (air gap model), only heat flow by conduction is considered through the air gap, due to the very small thickness of this layer $(1 \mathrm{~mm})$.

The thermal properties of the materials are temperature dependent and vary according to the standards used for composite slabs (CEN- European Committee for Standardization, 2005b), steel structures (CEN- European Committee for Standardization, 2005a) and concrete structures (CEN- European Committee for Standardization, 2004a). Presently, there is no standard which specifies the thermal properties of air. However, computer programs and experimental tests provide reliable data for numerical analyses. This investigation considers the thermal properties of air at $1 \mathrm{~atm}$ pressure (Çengel \& Ghajar, 2015). The thermal properties of steel, concrete and air are presented in Figure 4. Regarding the conductivity of concrete, the upper limit was selected for the numerical simulations. The specific heat of concrete presents a peak value related to $3 \%$ of moisture content of concrete weight. In this study, the extrapolation method is used to update the peak value for the moisture content of $3.5 \%$ regarding the Hamerlinck slab.

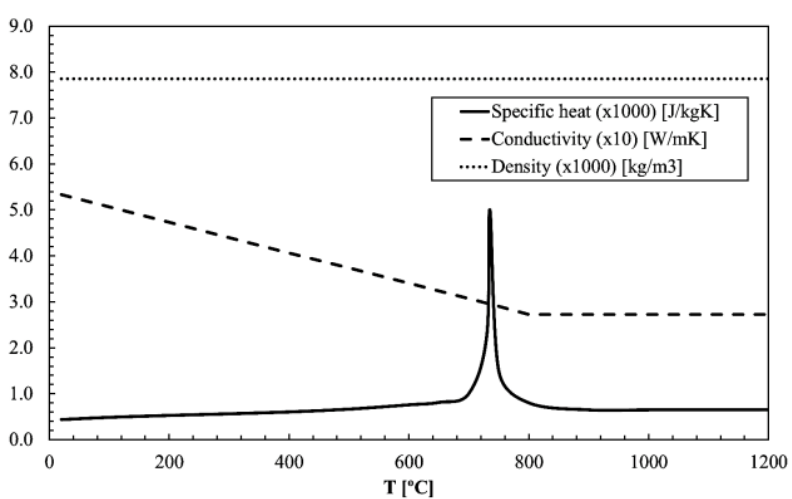

a) Carbon steel

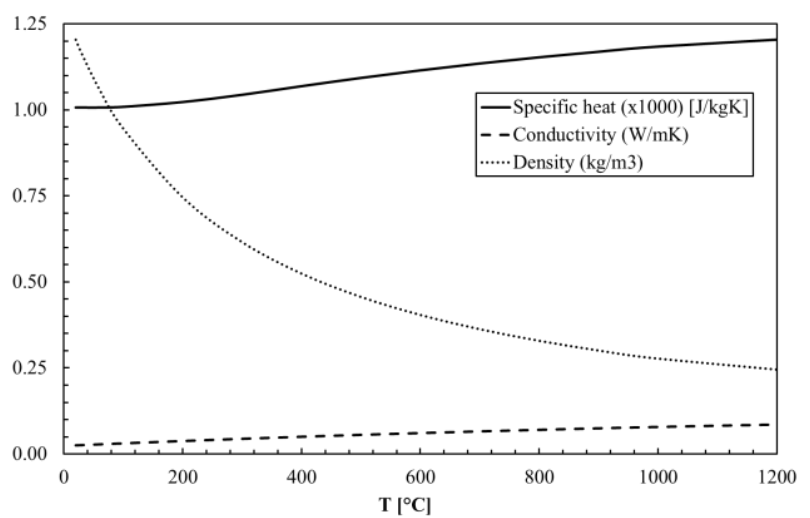

c) Air

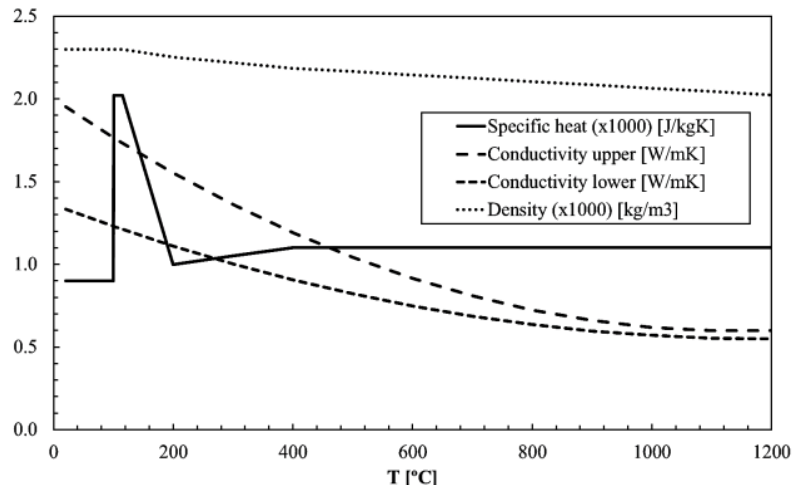

b) Concrete 


\section{Figure 4: Thermal Properties of Materials}

All the nodes are set with an initial condition for temperature of $20{ }^{\circ} \mathrm{C}$. The exposed side is submitted to a heat flux by convection and radiation, see Eq. 2, using different values for view factors and a bulk temperature following the standard fire. The unexposed side is subjected to a convective heat flux, using a constant bulk temperature of $20^{\circ} \mathrm{C}$. The lower part of the steel deck is subjected to standard fire conditions using a convection coefficient of $25 \mathrm{~W} / \mathrm{m}^{2} \mathrm{~K}$ and an emissivity of fire equal to 1 , see Figure 5 . A convective coefficient of $9 \mathrm{~W} / \mathrm{m}^{2} \mathrm{~K}$ is applied on the upper part of the composite slab in order to include the radiation effect (CEN- European Committee for Standardization, 2002). With respect to the convergence criteria, the heat flow criterion is applied on ANSYS, using a tolerance value of $10^{-3}$ and a minimum reference value of $10^{-6}$. On MATLAB, a value of $10^{-2}$ is set to the absolute tolerance and $10^{-1}$ to the relative tolerance, using a maximum number of Gauss-Newton iterations of 15.

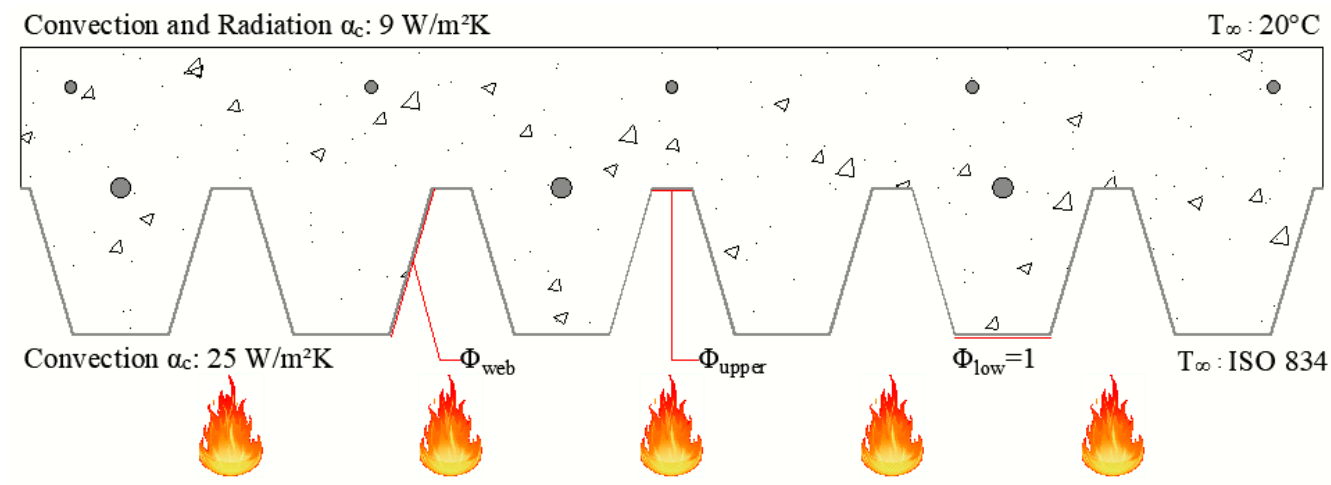

Figure 5: Representation of the Boundary Conditions for the Thermal Model

Figure 6 presents the temperature development (numerical and experimental) at different selected points, as well as the average and maximum temperatures at the unexposed side of the slab.

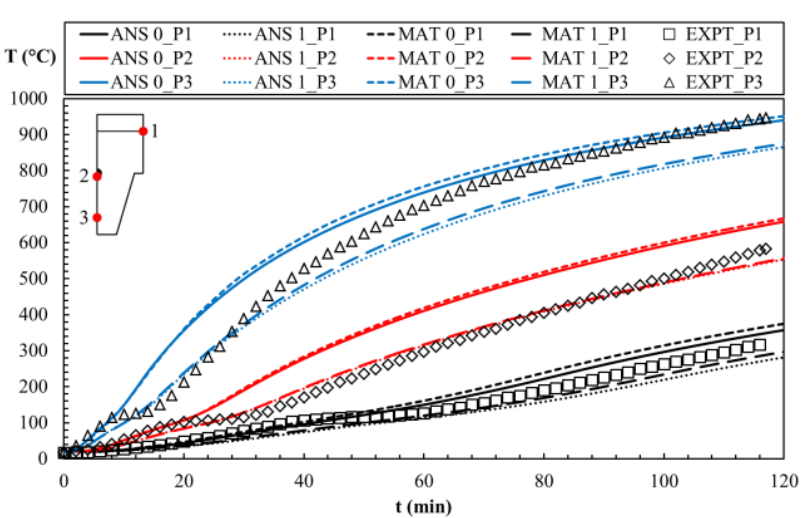

a) Selected points

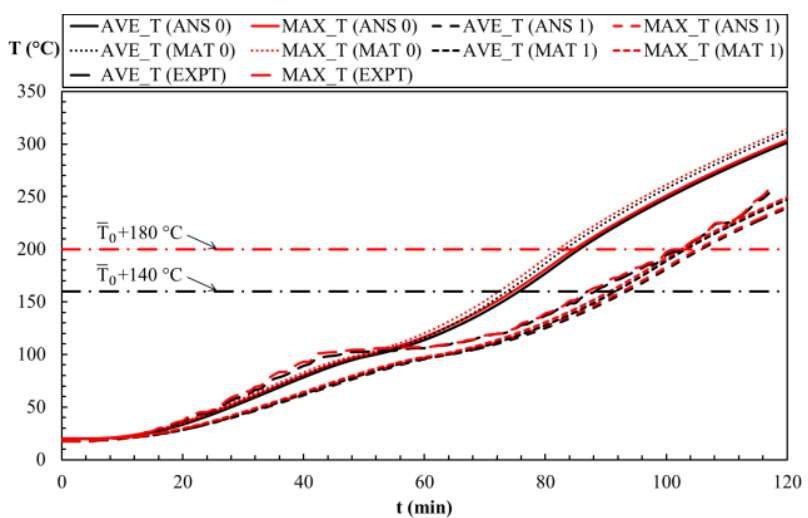

b) Unexposed side 
Figure 6: Numerical and Experimental Results - Points 1, 2 and 3 at distance 20, 74 and 123 mm from the Top

It can be observed that the temperature development on the selected points is quite similar between the experimental (EXPT) and the perfect contact models (ANS 0 and MAT 0) at the first minutes of heating. After that, better results are obtained using the air gap models (ANS 1 and MAT 1), with exception to point 3. This is because during a fire, the debonding of the steel deck from concrete occurs after a period of time. Regarding the temperature development on point 2 , the air gap models present good agreement with experimental results for temperatures over 100 ${ }^{\circ} \mathrm{C}$. For point 3, the perfect contact model presents better agreement with measured temperature in comparison to the air gap model, at the last minutes of heating. Concerning the temperature development on the unexposed surface, the maximum and average temperature curves are very close to each other for all the models. In this case, better agreement with the experimental results is observed using the air gap models. In general, small differences between the results of ANSYS and MATLAB models are observed. With respect to the results of the perfect contact models, ANSYS provides better agreement with experimental results in comparison to MATLAB for the selected points and the unexposed side as well. The opposite is observed for the air gap model, that is, MATLAB results are slightly closer to experimental results when compared to ANSYS results.

Table 1 presents the results obtained for the fire resistance according to the insulation criterion with respect to the average temperature rise $\left(t_{f i}\right.$ Ave $)$ and the maximum temperature rise $\left(t_{\mathrm{fi}} \mathrm{Max}\right)$ on the unexposed surface, for the validation model.

Table 1: Fire Resistance for Insulation Criterion: Experimental, Numerical and Analytical

\begin{tabular}{|l|l|l|l|l|l|l|}
\hline \multirow{2}{*}{ Fire resistance } & $\begin{array}{l}\text { Model } \\
\text { ANS 0 }\end{array}$ & $\begin{array}{l}\text { Model } \\
\text { MAT 0 }\end{array}$ & $\begin{array}{l}\text { Model } \\
\text { ANS 1 }\end{array}$ & $\begin{array}{l}\text { Model } \\
\text { MAT 1 }\end{array}$ & $\begin{array}{l}\text { EXPT } \\
\text { result }\end{array}$ & $\begin{array}{l}\text { EN 1994-1-2 } \\
\text { tfi Ave (min) }\end{array}$ \\
\cline { 1 - 6 } tfi Max (min) & 75.6 & 73.6 & 93.5 & 91.6 & 88.2 & \multirow{2}{*}{106.5} \\
\cline { 1 - 5 } & 84.8 & 82.0 & 105.1 & 102.5 & 102.1 & \\
\hline
\end{tabular}

Assuming the experimental result as reference, it can be observed that the air gap models slightly overestimated the fire resistance, with a relative error of $6.0 \%$ for ANSYS and $3.9 \%$ for MATLAB. A bigger discrepancy is obtained using the perfect contact models, with a relative error 
of $14.3 \%$ for ANSYS and 16.6\% for MATLAB. The EN 1994-1-2 provisions overestimated the fire resistance, providing an unsafe result with a relative error of $20.7 \%$.

The thickness of the air layer used in the air gap model $(1 \mathrm{~mm})$ was determined from a parametric analysis, selecting the value that best fit with the experimental data.

Figure 7 presents the temperature field of the composite slab at the end of the simulation (120 minutes) for ANSYS and MATLAB models, considering perfect contact between the materials.

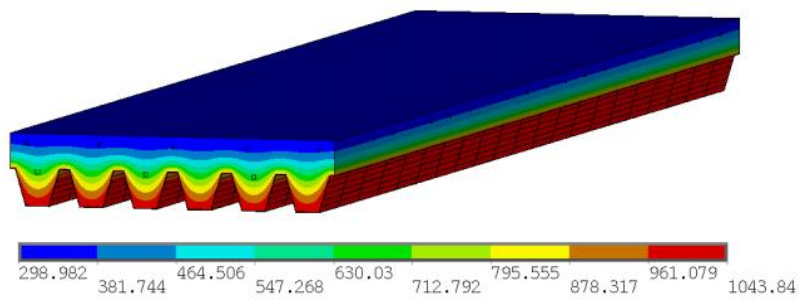

a) ANSYS

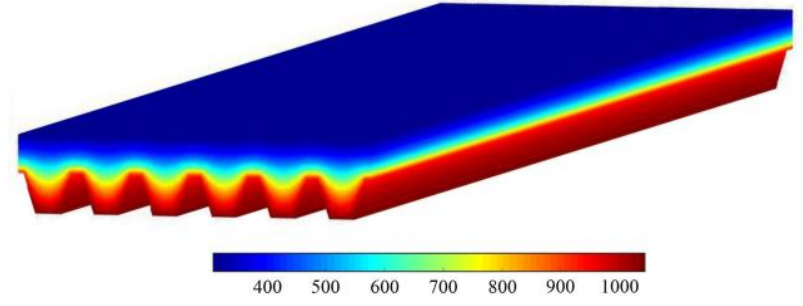

b) MATLAB

Figure 7: Temperature Field of the Slab at 120 min of Simulation (Perfect Contact Model)

\subsection{Mechanical Model}

In order to evaluate the fire resistance according to the load bearing criterion (R), the incremental and iterative solution method is presented, using the ANSYS perfect contact modelled slab. This solution method requires non-linear material behaviour, as the values of mechanical properties of steel and concrete depends on temperature.

Simple supported conditions were applied in the model, see Figure 8, and loads were applied through lines over nodes of the mesh.

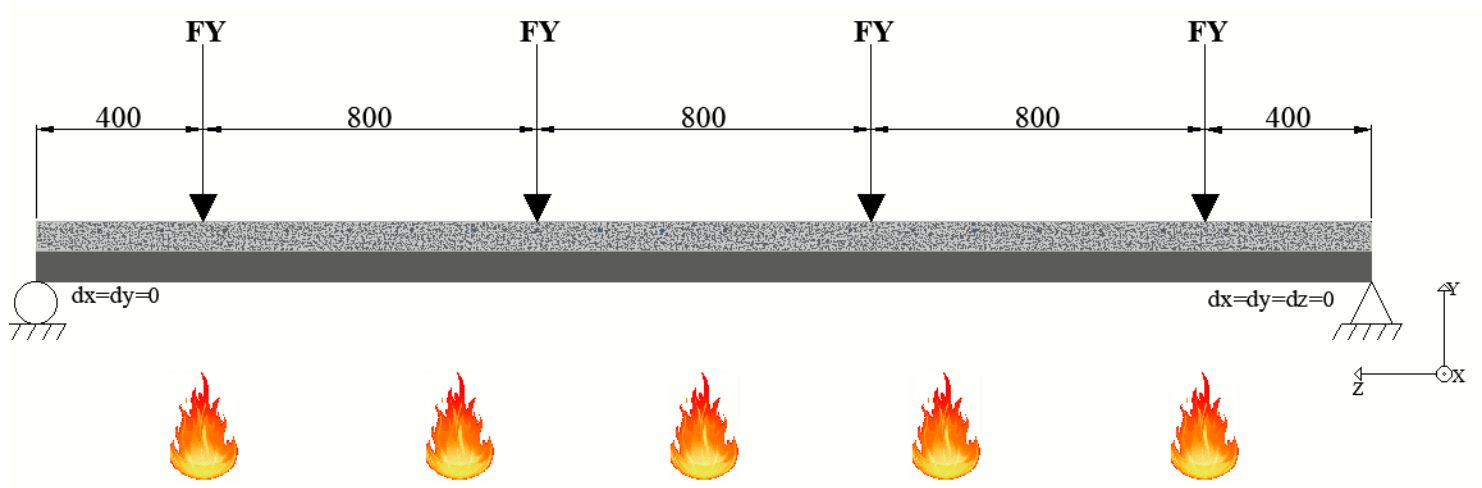

Figure 8: Support Conditions and Loads Configuration of ANSYS Mechanical Model

As presumption, no influence of the deformed shape was considered over the temperature distribution on the slab, also, large displacement behaviour was considered, being the equilibrium 
performed in the deformed configuration, for each time step of 60 seconds. With respect to the convergence criteria, force and moment analysis were used, with a tolerance value of $10^{-3}$ and a minimum reference value of $10^{\circ}$.

The design values for the material properties are in accordance with the experimental data reported (R. Hamerlinck \& Stark, 1990), and follow the temperature dependence variation, see Figure 9, proposed by the Eurocodes EN 1992-1-2 (CEN- European Committee for Standardization, 2004) for concrete and EN 1993-1-2 (CEN- European Committee for Standardization, 2005) for steel.

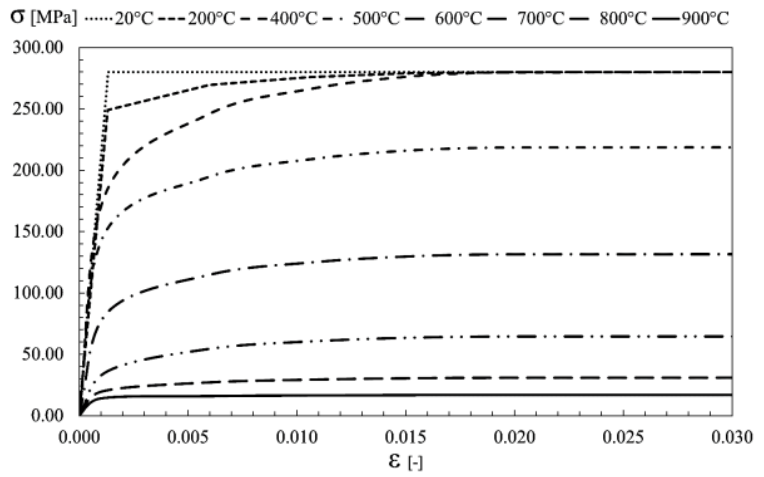

a) Mechanical Properties of Galvanized Steel

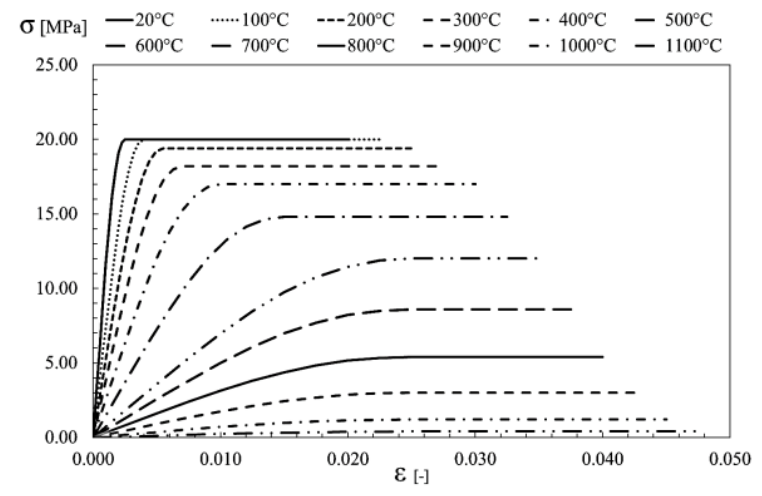

c) Mechanical Properties of Concrete

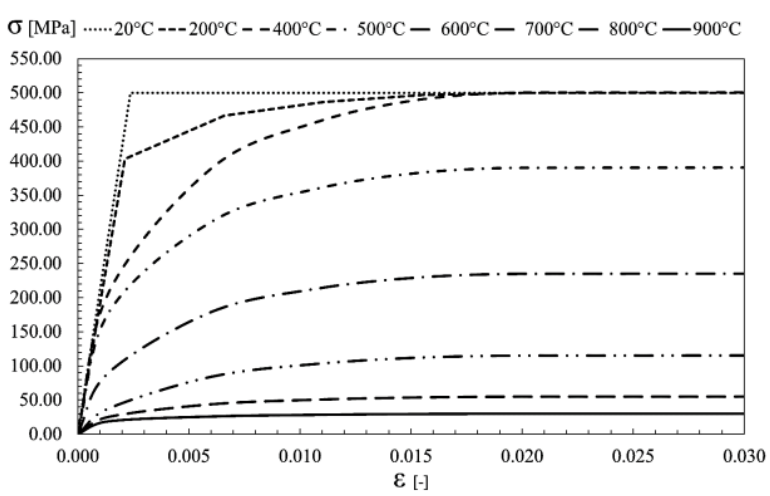

b) Mechanical Properties of Reinforcement

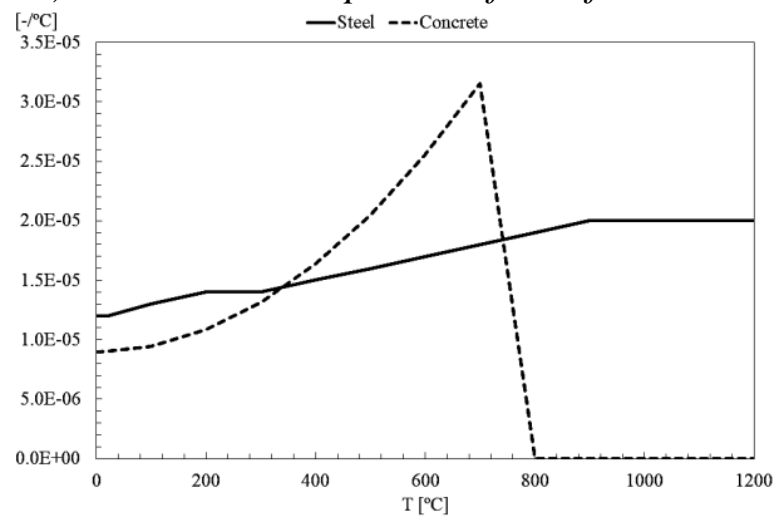

d) Coefficients of Thermal Expansion

Figure 9: Mechanical Properties for all Materials

The maximum displacement and the rate of the maximum displacement should be verified. Figure 10 represents the comparison between the experimental results and the numerical results. The critical time was determined by the first to achieve the limiting conditions presented in EN1363-1 (CEN- European Committee for Standardization, 2012). The vertical displacement of the slab changes with time. The curvature of the slab starts increasing rapidly and deflections increase accordingly. In a second stage, the deflection rate decreases as thermal curvature increases 
less. Near the ultimate limit state, the deflection rate increases again due to the plastic material behaviour. The limit for the rate of displacement was not achieved, being the numerical results in agreement with the experimental results.

For the mechanical model, it should be highlighted that the thermal load was determined based on the perfect contact model between materials (ANS 0). That is, the effect of the air gap between the steel deck and concrete was not considered. This fact results in higher temperature values for the materials and explains the higher predicted values for the vertical displacement of the numerical results.

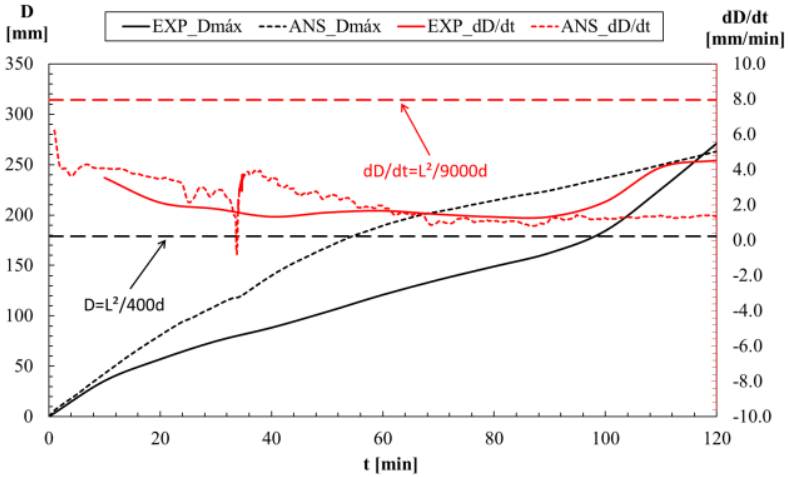

a) Time History for Displacement and Rate of Displacement

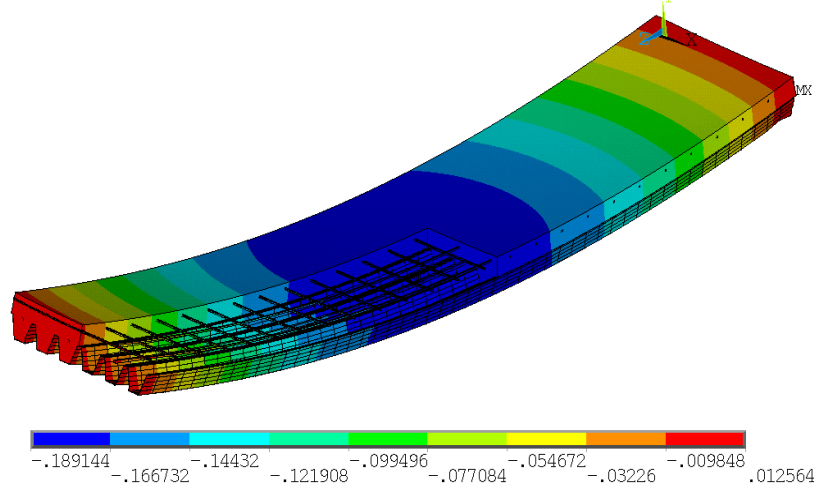

b) Deflection of the Slab for the Critical Time

Figure 10: Analysis of the Composite Slab with a live load of $2.7 \mathrm{kN} / \mathrm{m}^{2}$, under fire

Table 2 presents a comparison for the mechanical model, using perfect contact model, the results obtained from experimental tests and the results using the simple calculation procedure of EN1994-1-2, for the constant live load $\left(2.70 \mathrm{kN} / \mathrm{m}^{2}\right)$ and dead load $\left(2.80 \mathrm{kN} / \mathrm{m}^{2}\right)$. The maximum loadbearing capacity for 120 minutes is $6.63 \mathrm{kN} / \mathrm{m}^{2}$.

Table 2: Fire Resistance for Load Bearing (R): Experimental, Numerical and Analytical Results

\begin{tabular}{lccc}
\hline & Model ANS 0 & EXPT result & EN 1994-1-2 result \\
\hline $\mathbf{t}_{\mathbf{f i}} \mathbf{D}(\mathbf{m i n})$ & 78 & 97 & 120 \\
$\mathbf{t}_{\mathbf{f i}} \mathbf{d D} / \mathbf{d t}(\mathbf{m i n})$ & Not achieved & Not achieved & \\
\hline
\end{tabular}

The difference between both results can be explained by several factors, mainly by the temperature field in each time step. Other parameters are also reported and are related with several phenomena during the test (variation of the view factors, creation of the air gap effect between the 
steel deck and concrete, restrain effect in the supports, direction of the applied load during the test, among others).

\section{Parametric Study}

Parametric analyses are presented with the objective of determining the influence of concrete thickness and load level on the fire resistance of the slab, taking into consideration the insulation criterion (I) and the Load bearing capacity (R), respectively.

\subsection{Concrete Thickness - Criterion I}

A parametric analysis is conducted using the perfect contact model in order to determine the influence of the concrete thickness on the fire resistance according to the thermal insulation criterion. The trapezoidal steel deck profile "O FELIZ H60" has been selected, using normal weight concrete. The thickness of the concrete layer $\mathrm{h}_{1}$ was changed for 50, 60, 70, 80, 90, 100 and $110 \mathrm{~mm}$. Figure 11 illustrates the results for fire resistance (I) obtained using the EN 1994-12 calculation method, the ECCS technical note and the new proposal.

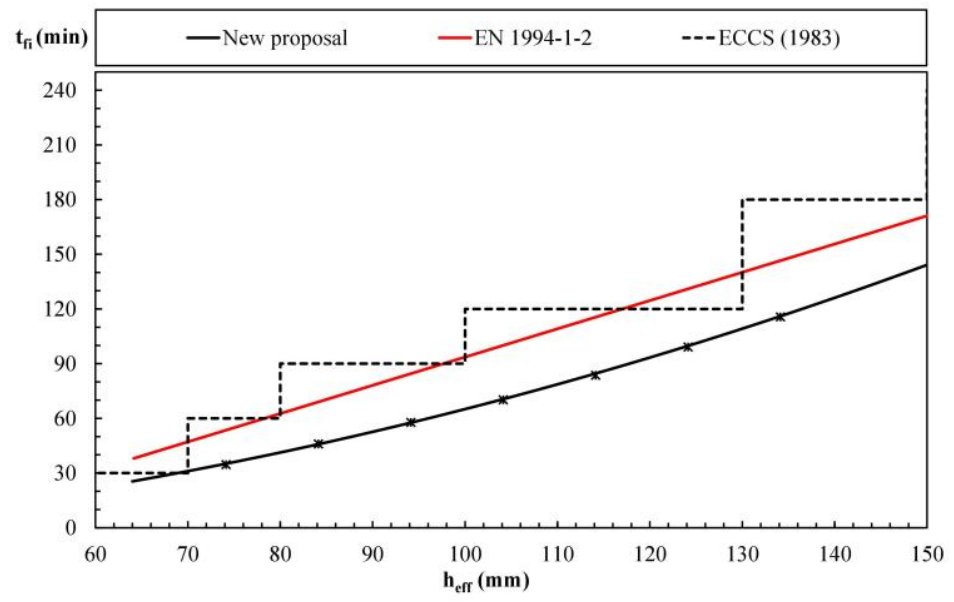

Figure 11: Comparison between the New Proposal and Standards Results

A proposal new equation is given, presenting a quadratic dependence between the fire resistance $t_{f i}$ and the effective thickness of the slab $h_{\text {eff, see }}$ Eq. 5.

$$
t_{f i}=0.0056 \cdot h_{e f f}^{2}+0.1823 \cdot h_{e f f}-9.1445
$$

\subsection{Load Level - Criterion $R$}

A parametric analysis was also developed, in order to verify the effect of the live load on the fire resistance. The load level, $\mu_{0}$, was determined by the ratio of the total load (live and dead) 
by the plastic load at room temperature, proposed by the EN 1994-1-1 (CEN- European Committee for Standardization, 2004b). The live load changed from $1.0 \mathrm{kN} / \mathrm{m}^{2}$ to $21.0 \mathrm{kN} / \mathrm{m}^{2}$.

The fire resistance decreases with the load level, see Figure 10, considering both calculation methods (Numerical and Simplified Calculation method). The fire resistance is overestimated by the simple calculation method for smaller load levels and underestimated for higher load levels. The critical temperatures of the steel components were determined based on the fire resistance criteria. These values also decrease with the load level. The fire resistance for load bearing criterion was exclusively governed by the critical displacement value (D). The rate of displacement $(\mathrm{dD} / \mathrm{dt})$ did not reach the critical value for load level values below $\mu_{0}=43 \%$. For higher load levels, the critical displacement rate becomes important, but never anticipates the time for the critical displacement. The thermal gradient can be easily determined for each load level, being approximately equal to $700{ }^{\circ} \mathrm{C} / 143 \mathrm{~mm}$ in the vertical direction. This value seems to be independent of the load level, see Figure 12.

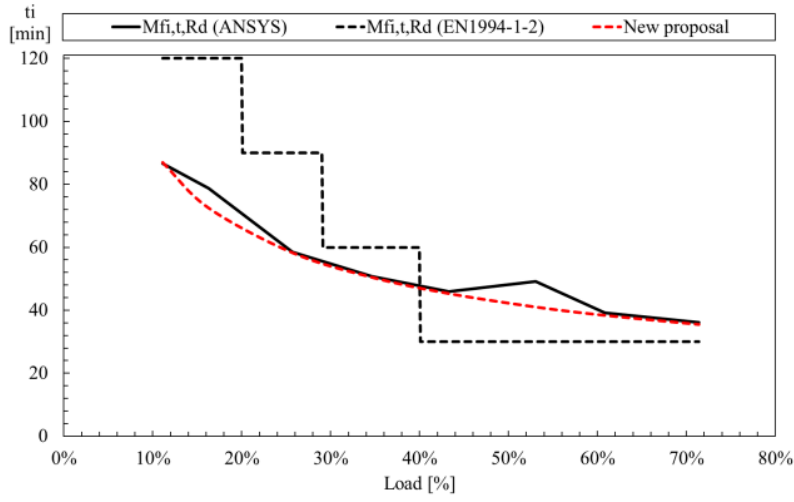

a) Fire Resistance

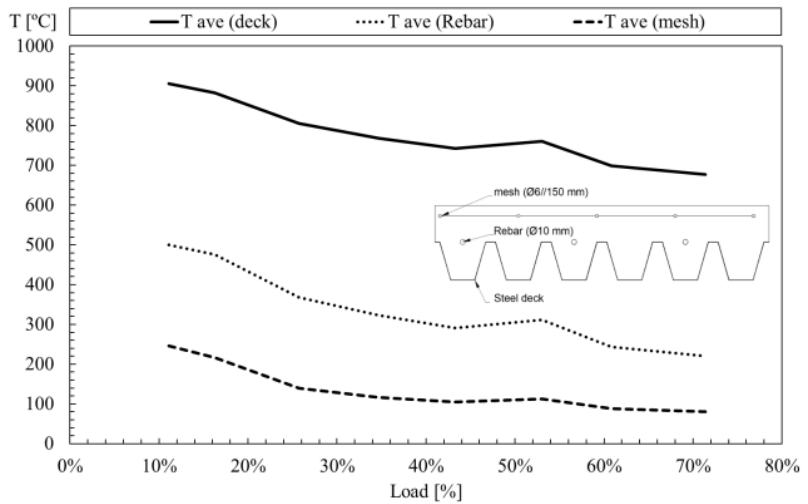

b) Critical Temperature

Figure 12: Fire resistance and critical temperature for the steel components

The fire resistance was approximated with the safety level, considering the results of the new proposal bellow the line of the numerical results. The new formula is presented in Eq.6.

$$
t_{f i}=32.104 \mu_{0}^{-0.464}-2
$$

In practice, rebars should be applied to composite slabs with steel deck in cases when the required fire resistance time is higher than 30 minutes. When these elements are submitted to fire exposure, the contribution of the steel deck to the load bearing resistance decreases considerably, being part of this capacity transferred to the rebars.

\section{Conclusions}


This investigation presented the description of thermal and mechanical three-dimensional numerical models as well as its validation against experimental data. The fire resistance according to the insulation (I) and load bearing (R) criteria was evaluated and compared to experimental results and the simplified calculation method of Eurocode 4 as well. For the thermal model, an alternative model was used in order to simulate the effects of debonding of the steel deck from concrete with the introduction of an insulating layer (air gap) between the concrete and steel deck.

Regarding the results for the temperature development, a plateau at about $100{ }^{\circ} \mathrm{C}$ (due to moisture evaporation) should be highlighted, consisting of a decrease in the rate of temperature increase. The results of the numerical simulations do not present this pronounced plateau, probably because localized moisture concentrations in the test was higher than the uniform moisture content introduced in the thermal model.

With respect to the numerical and experimental results for the validation of the thermal model, the average temperature rise criterion was decisive for the fire resistance according to the insulation criterion. The Eurocode 4 provisions overestimated the fire resistance providing an unsafe result, that is, the calculated fire resistance was greater than the results obtained in the experimental fire test. The perfect contact models underestimated the fire resistance. Therefore, it is evident that the air gap models provide better results for fire resistance from the thermal insulation standpoint when compared to the perfect contact models. Results from ANSYS and MATLAB were very close to each other for both perfect contact and air gap models.

Concerning the thermal model, a new proposal for the calculation of the fire resistance (I) was derived from a parametric analysis using the perfect contact model. The new equation presents a quadratic dependence between the fire resistance and the effective thickness of the slab. It should be highlighted that, although providing better results for the fire resistance, it is difficult to determine a formulation comprising the air gap model, because the thickness of the air layer which best fit with experimental results varies from slab to slab.

A new proposal for the load bearing resistance was also presented. The fire resistance decreases with the load level of the composite slab. The proposal presents smaller fire resistance when compared to the simplified calculation method, for load levels below 40\%, and higher fire resistance for load levels above this value. 
Future works should consider studying different types of steel deck geometry for both insulation (I) and load bearing (R) criteria and how the concrete thickness and load level could affect the fire resistance of those structures.

In addition, it is recommended for future research the variation and implementation of different parameters mainly on thermal analysis such as the emissivity of the steel deck (exposed surface), for example, intending to increase the precision of the simulation in every stage of fire.

\section{References}

Both, C. (1998). The fire resistance of composite steel-concrete slabs. Technical University of Delft.

CEN- European Committee for Standardization. (2002). EN 1991-1-2, Eurocode 1: Actions on structures - Part 1-2: General actions - Actions on structures exposed to fire. (CENEuropean Committee for Standardization, Ed.), CEN- European Committee for Standardization. Brussels: CEN- European Committee for Standardization.

CEN- European Committee for Standardization. (2004a). EN 1992-1-2: Design of concrete structures - Part 1-2: General rules - Structural fire design. (CEN- European Committee for Standardization, Ed.), CEN- European Committee for Standardization (Vol. EN 1992). Brussels: CEN - European Committee for Standardization.

CEN- European Committee for Standardization. (2004b). EN 1994-1-1: Design of composite steel and concrete structures - Part 1-1: General rules and rules for buildings. (CEN- European Committee for Standardization, Ed.). Brussels: CEN - European Committee for Standardization.

CEN- European Committee for Standardization. (2005a). EN 1993-1-2: Design of steel structures - Part 1-2: General rules - Structural fire design Eurocode. (CEN - European Committee for Standardization, Ed.). Brussels: CEN - European Committee for Standardization.

CEN- European Committee for Standardization. (2005b). EN 1994-1-2: Design of composite steel and concrete structures. Part 1-2: General rules - Structural fire design. (CEN- European Committee for Standardization, Ed.), CEN- European Committee for Standardization. Brussels: CEN- European Committee for Standardization.

CEN- European Committee for Standardization. (2012). EN 1363-1: Fire resistance tests Part 1 : General Requirements. (CEN- European Committee for Standardization, Ed.) (CEN- 
Europ). Brussels: CEN- European Committee for Standardization.

CEN - European Committee for Standardization. EN 1365-2: Fire resistance tests for load bearing elements - Part 2: Floors and roofs (Withdrawal) (2014). Brussels.

Çengel, Y. A., \& Ghajar, A. J. (2015). Heat and mass transfer: fundamentals \& applications (Fifth edit). New York: McGraw-Hill Education.

European Convention for Constructional Steelwork - Committee T3 - Fire Safety of Steel Structures. (1983). Calculation of the fire resistance of composite concrete slabs with profiled steel sheet exposed to the standard fire. ECCS: Publication 32, 48.

Guo, S., \& Bailey, C. G. (2011). Experimental behaviour of composite slabs during the heating and cooling fire stages. Engineering Structures, 33, 563-571. https://doi.org/10.1016/j.engstruct.2010.11.014

Hamerlinck, A. F. (1991). The behaviour of fire-exposed composite steel/concrete slabs. Eindhoven University of Technology. https://doi.org/10.6100/IR348360

Hamerlinck, R., \& Stark, J. W. B. (1990). A numerical model for fire-exposed composite steel / concrete slabs. In Wei-Wen Yu and Roger A. LaBoube (Ed.), 10th International Specialty Conference on Cold-Formed Steel Structures - International Specialty Conference on Cold-Formed Steel Structures. 5. (pp. 115-130). St. Louis, Missouri.

Hamerlinck, R., \& Twilt, L. (1995). Fire resistance of composite slabs. Journal of Constructional Steel Research, 33(94), 71-85. https://doi.org/10.1016/0143-974X(94)00015-A

International Organization for Standardization. (1999). ISO 834-1: Fire Resistance Tests Elements of Building Construction - Part 1: General Requirements. Switzerland: International Organization for Standardization.

Jiang, J., Pintar, A., Weigand, J. M., Main, J. A., \& Sadek, F. (2019). Improved calculation method for insulation-based fire resistance of composite slabs. Fire Safety Journal, 105, 144-153. https://doi.org/10.1016/j.firesaf.2019.02.013

Li, G.-Q., Zhang, N., \& Jiang, J. (2017). Experimental investigation on thermal and mechanical behaviour of composite floors exposed to standard fire. Fire Safety Journal, 89(November), 63-76. https://doi.org/10.1016/j.firesaf.2017.02.009

Lim, L., \& Wade, C. (2002). Experimental fire tests of two-way concrete slabs. Christchurch. 